\title{
Linguistic Strategies for Western Cosmetic Brand Translation in China
}

\author{
Jiafeng Liu ${ }^{1}$ \\ ${ }^{1}$ School of Foreign Languages, Southwest Minzu University, Chengdu, China \\ Correspondence: Jiafeng Liu, School of Foreign Languages, Southwest Minzu University, Chengdu, China. \\ E-mail: 378411817@qq.com
}

Received: August 20, 2017

Accepted: September 20, 2017

Online Published: October 18, 2017

doi:10.5539/ijbm.v12n11p164

URL: https://doi.org/10.5539/ijbm.v12n11p164

This paper is supported by the Fundamental Research Funds for the Central Universities, Southwest Minzu University (Grant No. 2015SZYQN131).

\begin{abstract}
Based on an aim-adaptation approach, this article investigates the linguistic strategies used by 126 western cosmetic brands in their Chinese renaming. Firstly, the linguistic features of the original English brand names and the translated Chinese names are summarized and compared. Secondly, the specific features reflected in the translating process are summarized. Our analysis shows that adaptations from phonetic, lexical and semantic components of the name should be adopted to meet the aims and needs of the cosmetic brand and its customers.
\end{abstract}

Keywords: adaptation theory, brand name, renaming; translation, linguistic strategy

\section{Introduction}

A brand name conveys a variety of meanings, both literally through its actual meaning (if it has one) and connotatively through its sound and the variety of associations and public meanings it has built up through use over time (Gardner and Levy 1955). As more and more companies provide their products and services across markets where languages and cultures are different, a translated brand name, which represents a variety of ideas or attributes desired by the brand and promotes brand sales, is every brand's dream, especially when lots of inappropriate translated names failed the sales promotion of their brand products and services in the specified target markets. For instance, Coca Cola, the world famous American beverage brand, had a poor performance in Chinese market when it first entered China at the beginning of 20th century partly because of its inappropriate translated name meaning "bite the wax tadpole" in Chinese. Therefore, based on an aim-adaptation approach, the author makes empirical research on the linguistic features of the English and Chinese names of 126 Western cosmetic brands in Chinese market, so as to explore effective linguistic strategies of Western cosmetic brands renaming in China, with a hope to expand research dimensions in the pragmatic translation theories. In this paper, we chose the western cosmetic brands whose names were included in this study and whose products were available in Chinese market. We downloaded brands from the popular Chinese web sites such as JD, BAIDU, PPZW. We selected only cosmetic brands with both English and Chinese names in order to investigate the linguistic strategies for western cosmetic brand translation. Accordingly, we collected all original English brand names of the 126 cosmetic brands on their company home pages and their Chinese brand names on their Chinese home page (if available).

\section{Literature Review}

\subsection{An Aim-Adaptation Approach}

According to the German Functionalist Skopos theory (Vermeer 1989; Nord 1997), the translated version is contingent on the text functions and the translation purposes of the clients and the translators. Mengzhi Fang (2011) holds that the translation of pragmatic texts depends on the purposes of the clients and the translators and the specific text functions. The original English text and the translated Chinese text, with possible different purposes and functions, are two independent ones with different values for their targeted consumers in English and Chinese markets respectively. As the aim-needs of the clients and the targeted customers are the decisive factors, the translator selects part of the intended information in the original text or creates new meaning desired by the clients and the targeted customers in the translated version. According to Verschueren(1999), using 
language consists of "the continuous making of linguistics choices" reflecting three interrelated properties of language, namely, variability, negotiability, and adaptability. Above all, adaptability is the property of language which enables human beings to make negotiable linguistic choices from a variable range of possibilities in such a way as to approach points of satisfaction for communicative needs. Combining the German Functionalist Skopos theory and the theory of adaptation by Verschueren in 1999, Lisha Zeng (2014) suggests an aim-adaptation approach. He argues that, during the translation of pragmatic texts, it is necessary for the translators to take the aim-needs of the clients into consideration as well as those of the customers, accordingly, and employ translation strategies with the guide of the theory of adaptation.

\subsection{The Importance of Brand Name}

Brands with strong images are able to influence customers' choices and command a premium in the marketplace (Kohli \& Labahn, 1997). A brand name, as a linguistic sign of a brand and the foundation of a brand's image, conveys brand meaning, helps position the brand (Wind 1982), and has a direct influence on brand awareness and brand association. A carefully created and chosen name can bring inherent and immediate value to the brand. It has been argued that only the best-managed and strongest brand names will survive because a good brand name has desirable properties, such as positive connotations associated with the brand name, relevance to the product, memorability, and the ability to offer a distinctive image over competing products (Kohli and LaBahn 1997). Consequently, one of the most important decisions for a company is to create an effective brand name for its products or services. Similarly, during the internationalization of a brand, one of the most important decisions is to get a desired translated brand name. Therefore, it is crucial to linguistically adapt to the aim-needs of the target market, spread the information the brand desires, and attract the interests of the target consumers effectively.

\subsection{Brand Name Translation}

The vast literature on brand name translation is generally divided into the study of translation methods, the factors influencing the choices of translation methods, and the translation strategies. In terms of brand name translation methods, especially from English to Chinese, marketing scholars and translators usually categorize them into the following groups. Dong, Lily and Helms (2001) classifies the brand translation methods into five types - free translation, literal translation, literal translation with meanings created and literal translation with meaning modified, literal translation with meanings lost. Zhang \& Schmitt (2001) distinguished three translation methods: phonetic (i.e. by sound), semantic (i.e. by meaning) and phonosemantic (i.e. sound plus meaning). Hong, Pecotich and Schultz (2002) espouse two methods: (1) direct translation for the meaning of the brand name and (2) phonetic translation for the pronunciation of the brand name. Following two linguistic dimensions: relatedness in sound (that is, phonemes) and relatedness in meaning (that is, semantics), Schmitt and Zhang (2012) hold that there are four possible types of name translations from English to Chinese: a translation based on sound; a translation based on meaning; a translation based on sound and meaning; creative translation. In terms of the factors influencing the choices of translation methods, most scholars mentioned cultural factors, political factors and historical factors (Dong \& Helms, 2001; Li \& Shooshtari, 2003; Jiafeng Liu, 2015). Many authors focus on the linguistic differences between Chinese and English brand names (Francis, Lam, \& Walls, 2002; Usunier \& Shaner, 2002; Jiafeng Liu, 2015). In terms of the translation strategies, by comparing English brand names with Chinese brand names on several linguistic dimensions, Francis et al. (2002) investigate the brand name standardization/ adaptation strategies used by consumer goods Fortune-500 companies in China and Hong Kong. Jiafeng Liu (2015), through distinguishing the forms and features of meanings and attached senses in examining brand names, explores the diachronic evolving rules of the multiple meaning-senses in translating brand names and thereupon puts forward three relevant strategic translating principles. Shiao-Yun Chiang (2008) explores the interconnection between language and globalization across linguistic and socio-cultural boundaries as exemplified in the transpositions of global brands from English into Chinese. Nevertheless, prior research neglected studying how to linguistically adapt the desired properties for brand names such as memorability, distinctiveness, recognizability, or suggestiveness of product features or benefits.

\subsection{Brand Name Translation Featuring the Nature of Aim-Adaptation}

With the inspiration of many legendary successes of English brands into the global market, many marketing scholars and translators realize what an ideal translated brand name means to the survival and flourishing of a brand. The commercial nature of a brand predetermines that brand translation is a type of market-oriented translation which requires the translator to adapt the aim-needs of the clients as well as those of the targeted consumers linguistically. As the brand company develops with the change of its products or services as well as the expansion from one country to another, the brand positioning and strategies may be different because they 
face different consumers with specific aim-needs. Namely, the meanings the brand has to convey in the translated name may completely differ from those the original brand name does. As a result, the translating of brands is not a simple decoding and encoding process but a linguistic adaptation of the aim-needs of the clients and the targeted consumers.

\section{A Comparative Analysis of Linguistic Features of Western Cosmetic Brand}

To explore the linguistic adaptation strategies during the process of brand translation, this part analyzes and compares the linguistic features of English and Chinese names of 126 Western cosmetics brands phonetically, semantically and lexically.

\subsection{Linguistic Features of English Names of Western Cosmetics Brands}

Linguistic features of English names of western cosmetics brands are analyzed and discussed in the following (See table 1).

Table 1. Linguistic features of English names of western cosmetics brands $(\mathrm{N}=126)$

\begin{tabular}{|c|c|c|c|c|}
\hline linguistically & \multicolumn{2}{|l|}{ Item } & $\mathrm{N}$ & Percentage of total \\
\hline \multirow[t]{6}{*}{ Phonetically } & \multicolumn{2}{|l|}{ One-syllable } & 5 & $4.0 \%$ \\
\hline & \multicolumn{2}{|l|}{ Two-syllable } & 41 & $32.5 \%$ \\
\hline & \multicolumn{2}{|l|}{ Three-syllable } & 51 & $40.5 \%$ \\
\hline & \multicolumn{2}{|l|}{ Four-syllable } & 18 & $14.3 \%$ \\
\hline & \multicolumn{2}{|c|}{ Five-syllable and above } & 11 & $8.8 \%$ \\
\hline & \multicolumn{2}{|c|}{ Common vocabulary } & 20 & $15.9 \%$ \\
\hline \multirow[t]{3}{*}{ Lexically } & \multicolumn{2}{|l|}{ Proper name } & 50 & $39.7 \%$ \\
\hline & \multicolumn{2}{|c|}{ Fabricated vocabulary } & 30 & $23.8 \%$ \\
\hline & \multicolumn{2}{|l|}{ Phrase } & 26 & $20.6 \%$ \\
\hline \multirow[t]{6}{*}{ Semantically } & \multirow[t]{2}{*}{ Literal meaning } & Yes & 126 & $100 \%$ \\
\hline & & No & 0 & 0 \\
\hline & \multirow[t]{2}{*}{ Core associations } & Reflected & 79 & $62.7 \%$ \\
\hline & & Not reflected & 47 & $37.3 \%$ \\
\hline & \multirow[t]{2}{*}{ Connotation } & Positive & 26 & $20.6 \%$ \\
\hline & & Neutral & 100 & $79.4 \%$ \\
\hline
\end{tabular}

\subsubsection{Analysis of Phonetics of English Names}

Phonetically, the syllabic structure of English names is investigated, and the distribution of them are as follows: of all 126 English names, the most frequent structure is three-syllable (51 or $40.5 \%$ ), a further 41 or $32.5 \%$ brand names have two syllables, 18 or $14.3 \%$ brand names have four syllables, 11 or $8.8 \%$ brand names have five syllables or above, and only 5 or $4 \%$ brand names have one syllable. The above results show that western cosmetics brand naming tends to use three-syllables and two-syllables, with a certain proportion of four-syllables and five-syllables and very few one-syllables. As English words usually consist of 2 or more syllables, most western cosmetics brands, following the word construction rules, adopt existed vocabulary including common words, proper terms and word combinations as well as coined words with 2 or 3 syllables, which are concise and easy for people to remember, one of the crucial brand naming principles.

\subsubsection{Lexical Analysis of English Names}

Lexically, the word sources of English names are investigated, and the distribution of them are as follows: of all 126 English names, the most common brand names are proper names (50 or $39.7 \%$ ), a further 30 or $23.8 \%$ of brand names are fabricated vocabulary, 26 or $20.6 \%$ are phrases, and 20 or $15.9 \%$ are common vocabulary. The above results show that western cosmetics English brand naming tends to use proper names, with a certain proportion of fabricated vocabulary, phrases and common vocabulary, which reflects the long history of western cosmetics naming. Lots of brands, established in the early $19^{\text {th }}$ century, are named with the surname of the founder of the company, the names of plant, river, and place.

\subsubsection{Semantic Analysis of Semantic of English Names}

Semantically, the literal meaning, core associations and connotation of English names are investigated. According to table 1, all 126 brand names (100\%) have literal meaning; 79 brand names (62.7\%) have reflected core associations of the brand while 47 English names haven't reflected; 26 brand names (20.6\%) have positive 
connotations while 100 brand names (79.4\%) have neutral connotations. As mentioned above, all English names investigated have literal meanings, most English names reflected core associations, and have neutral connotations. The data show that western cosmetics brand naming prefers words with literal meanings, core associations, and neutral connotations.

\subsection{Linguistic Features of Chinese Names of Western Cosmetics Brands}

Linguistic features of Chinese names of western cosmetics brands are analyzed and discussed in the following (See table 2).

Table 2. Linguistic features of Chinese names of western cosmetics brands $(\mathrm{N}=126)$

\begin{tabular}{|c|c|c|c|c|}
\hline Linguistically & \multicolumn{2}{|l|}{ Item } & $\mathrm{N}$ & Percentage of total \\
\hline & \multicolumn{2}{|l|}{ One-syllable } & 1 & $0.8 \%$ \\
\hline \multirow[t]{5}{*}{ Phonetically } & \multicolumn{2}{|l|}{ Two-syllable } & 28 & $22.2 \%$ \\
\hline & \multicolumn{2}{|l|}{ Three-syllable } & 68 & $54 \%$ \\
\hline & \multicolumn{2}{|l|}{ Four-syllable } & 22 & $17.5 \%$ \\
\hline & \multicolumn{2}{|c|}{ Five-syllable and above } & 7 & $5.6 \%$ \\
\hline & \multicolumn{2}{|c|}{ Common vocabulary } & 26 & $20.6 \%$ \\
\hline \multirow[t]{3}{*}{ Lexically } & \multicolumn{2}{|l|}{ Proper name } & 4 & $3.2 \%$ \\
\hline & \multicolumn{2}{|c|}{ Fabricated vocabulary } & 89 & $70.6 \%$ \\
\hline & \multicolumn{2}{|l|}{ Phrase } & 7 & $5.6 \%$ \\
\hline \multirow[t]{6}{*}{ Semantically } & \multirow[t]{2}{*}{ Literal meaning } & Yes & 36 & $28.6 \%$ \\
\hline & & No & 90 & 71.4 \\
\hline & \multirow[t]{2}{*}{ Core associations } & Reflected & 76 & $60.3 \%$ \\
\hline & & Not reflected & 50 & $39.7 \%$ \\
\hline & \multirow[t]{2}{*}{ Connotation } & Positive & 76 & $60.3 \%$ \\
\hline & & Neutral & 50 & $39.7 \%$ \\
\hline
\end{tabular}

\subsubsection{Phonetic Analysis of Chinese Names}

Phonetically, the syllabic structure of Chinese names is investigated, and the distribution of them are as follows: of all 126 English names, the most frequent structure is three-syllable $(68,54 \%)$, a further 28 or $22.2 \%$ of brand names have two syllables, 22 or $17.5 \%$ of brand names have four syllables, 7 or $5.6 \%$ of brand names have five syllables or above, only 1 or $0.8 \%$ is one-syllable. Compared with original English names, the translated Chinese brand names increased 17 three-syllables, 4 four-syllables, 4 one-syllables, and reduced 13 two-syllables and 4 five-syllables. According to the above statistical results, firstly, western cosmetics brand translating follows the principle of simplicity, selecting three-syllables and two-syllables; secondly, western cosmetics brand translating tends to take the features and roles of Chinese syllables into consideration.

\subsubsection{Lexical Analysis of Chinese Names}

Lexically, the word sources of Chinese names are investigated, and the distribution of them are as follows: of all 126 translated Chinese names, the most common brand names are fabricated vocabulary ( 89 or $70.6 \%$ ), a further 26 or $20.6 \%$ of brand names are common vocabulary, 7 or $5.6 \%$ are phrases, and only 4 or $3.2 \%$ are proper names. The above results show that western cosmetics Chinse brand translating, to attract consumers, tends to select fabricated vocabulary reflecting the characteristics and results of products.

\subsubsection{Semantic Analysis of Chinese Names}

Semantically, the literal meaning, core associations and connotation of the Chinese names are investigated. According to table 2, all 126 Chinese names, 36 brand names (28.6\%) have literal meaning while 90 brand names $(71.4 \%)$ have no literal meaning; 76 brand names $(60.3 \%)$ have reflected core associated meanings while 50 brand names $(39.7 \%)$ haven't reflected core associations; 76 brand names $(60.3 \%)$ have positive connotations while 50 brand names $(39.7 \%)$ have neutral connotations. As mentioned above, western cosmetic brand 
translating tends to select words without literal meanings but reflecting core associations, and have positive connotations.

\subsection{A Comparison of Linguistic Features of English and Chinese Names}

This part compares the linguistic features of English and Chinese names of 126 western cosmetics brands phonetically, lexically, and semantically. Phonetically, this paper compares the pronunciation similarities and simplicity of the translated Chinese names and their original English counterparts. Lexically, this paper compares the similarities of word sources. Semantically, this paper compares the similarities of literal meanings of both English and Chinese names, whether English and Chinese names reflect core associations of the brands, the connotations of English and Chinese names.

\subsubsection{Comparison of Phonetic Features (table 3)}

Table 3. Comparison of phonetic features between English and Chinese names $(\mathrm{n}=126)$

\begin{tabular}{lllll}
\hline The comparison of phonetic features & Items & N & Percentage of total \\
\hline English \& Chinese names & Pronunciation similarity & Similar & 84 & $66.7 \%$ \\
& & Not similar & 42 & $33.3 \%$ \\
& \multirow{2}{*}{ Length } & Same & 68 & $54 \%$ \\
& & Chinese name is shorter & 21 & $16.6 \%$ \\
& & Chinese name is longer & 37 & $29.4 \%$ \\
\hline
\end{tabular}

The degree of pronunciation similarity in a Chinese name is a crucial criterion to determine the degree of brand standardization. According to table 3, of all the brand names, the pronunciations of 84 Chinese names $(66.7 \%)$ are similar to their English counterparts, and the pronunciations of 42 Chinese names (33.3\%) are not similar to the English. The above data show most of Chinese cosmetics brand names have similar pronunciations with their English counterparts.

Simplicity is one of the characteristics that are related to memorability of brand names, which is measured with the length of the brand's name and the number of syllables that make up the brand name (Francis, Lam \& Walls, 2002). This paper compares the length of Chinese names with that of the English counterparts. Table 3 shows that 68 Chinese names (54\%) are as long as their English counterparts, 37 Chinese names (29.4\%) are longer than their English counterparts, and 21 Chinese names (16.6\%) are shorter than their English counterparts. The above statistical results show that most of Chinese names are as long as their English counterparts, some become longer, and some shorter.

\subsubsection{Comparison of Lexical Features (table 4)}

Table 4. Comparison of lexical features between English and Chinese names $(\mathrm{n}=126)$

\begin{tabular}{lllll}
\hline lexical feature & & Variation & N & Percentage \\
\hline Chinese \& English name & Common vocabulary & + & 6 & $20.6 \%$ \\
& Proper name & - & 46 & $3.2 \%$ \\
& Fabricated vocabulary & + & 59 & $67.4 \%$ \\
& Phrase & - & 19 & $5.6 \%$ \\
\hline
\end{tabular}

According to table 4, of all the brand names, the vast majority of Chinese names are not proper names and phrases but fabricated vocabulary and common vocabulary. Compared with the original English names, 59 more fabricated vocabulary $(67.4 \%)$ and 6 more Chinese common vocabulary $(20.6 \%)$ are adopted as brand names, whereas 46 proper names (3.2\%) and phrases (5.6\%) disappear in translated Chinese brand names. The data above show that word sources in translated Chinese names are much different from those in the original English names. 
3.3.3 Comparison of semantic features (table 5)

Table 5. Comparison of semantic features between English and Chinese names $(n=126)$

\begin{tabular}{llll}
\hline & \multicolumn{1}{c}{ Variation } & N & Percentage of total \\
\hline \multirow{3}{*}{ Literal meaning similarity } & Similar & 18 & $14.3 \%$ \\
& Dissimilar & 108 & $85.7 \%$ \\
& Only English names reflected & 23 & $18.3 \%$ \\
& Only Chinese names reflected & 21 & $16.7 \%$ \\
& Both Chinese and English names reflected & 54 & $42.9 \%$ \\
& Both Chinese and English names not reflected & 28 & $22.1 \%$ \\
& Negative & 0 & 0 \\
& Positive & 22 & $17.5 \%$ \\
& positive to neutral & 5 & $4.0 \%$ \\
& Neutral & 45 & $35.7 \%$ \\
& neutral to positive & 54 & $42.9 \%$ \\
& English cultural connotations remained & 10 & $8 \%$ \\
& English cultural connotations lost & 12 & $9.5 \%$ \\
& Chinese cultural connotations augmented & 47 & $37.3 \%$ \\
& English cultural connotations augmented & 57 & $45.2 \%$ \\
\hline
\end{tabular}

According to table 5, of all the brand names, semantically, 18 Chinese names $(14.3 \%)$ have similar literal meanings with their English counterparts, whereas 108 Chinese names (85.7\%) have different literal meanings. 23 English names (18.3\%) have reflected core associations of the brands while their Chinese counterparts haven't; 21 English names (16.7\%) haven't reflected core associations of the brands while their Chinese counterparts have; 54 English names and their Chinese counterparts $(42.9 \%)$ have reflected core associations of the brands; and 28 English names and their Chinese counterparts $(22.1 \%)$ haven't reflected core associations of the brands. 22 Chinese names (17.5\%) have positive connotations of their English counterparts; 5 translated Chinese names (4.0\%) have neutral connotations while their English counterparts are with positive connotations; 45 Chinese names (35.7\%) maintain neutral connotations of their English counterparts, 54 Chinese names (42.9\%) have positive connotations while their English counterparts are with neutral connotations. 10 Chinese names (8\%) maintain English cultural connotations; 12 Chinese names (9.5\%) have lost cultural connotations of their English connotations, 47 Chinese names (37.3\%) are infused with Chinese cultural connotations, and 57 translated names (45.2\%) are infused with English cultural connotations.

The above statistical results show that the majority of Chinese names have different literal meanings from their English counterparts, most of Chinese names have neutral connotations while their English counterparts have positive connotations, most of the translated Chinese brand names are infused with English or Chinese cultural connotations.

\section{Linguistic Adaptation Strategies for Western Cosmetic Brand Translation}

The results of this study suggest that linguistic adaptation strategies be adopted when western cosmetic brands expanding to Chinese markets.

\subsection{Phonetic Adaptation Strategies}

Phonetics is an important part of language. Two components of the translated brand name are pertinent to determine the degree of standardization and length of the translated name. The first is the pronunciation consistency between the translated name and the original one and the second is the syllabic length of the translated name. The above results show that, of all brand names investigated, the pronunciations of most Chinese names $(66.7 \%)$ are similar with those of their English counterparts, which reveals western cosmetic brands have mature branding systems. When it comes to the length of Chinese name, more than half of Chinese names (54\%) are as long as their English counterparts, whereas some Chinese names (29.4) become longer and some become shorter (16.6\%). Most western cosmetic brands have adopted pronunciation consistency and the same length between the translated Chinese name and the original English name because they intend to build same or similar brand images across different markets, which help their Chinese consumers get same or similar brand image recognition and believe the brand products represent high-quality and fashionable living standard, even a symbol of higher status. According to the studies in foreign branding (de Mooij, 2010), brand name is not 
only an extrinsic cue to the quality of brand products but also imply the origin of the product. Chinese consumers usually show positive attitudes and preference for nonlocal country of origin, especially from the west, compared to brands that were perceived as local (Villar, Ai, Segev, 2012). That is why many western cosmetic brands adopt phonetic adaptation strategy to trigger an association between brand names and country equity in consumer' minds, which helps generate perceptions about quality. For example, Estee Lauder, an American manufacturer and marketer of prestige skincare, makeup, fragrance and hair care products, is translated into Chinese "Ya shi lan dai” (雅诗兰黛). The pronunciation of the Chinese name is similar to that of the original English one and both Chinese and English names have 4 syllables while the literal meanings and associated meanings of the Chinese name are quite different from those of the English name. "Estee Lauder", the English brand name, is named after one of its founders and has been exploited, developed and reinforced in the advertising strategy and copy over a number of years, particularly through slogans that emphasize and reinforce the associated meanings, which were lost when crossing Chinese borders. "Ya shi lan dai" (雅诗兰黛), the Chinese name, is meaningless as a whole and characters in it has nothing to do with the literal meaning of "Estee Lauder" while each character is meaningful and can arose associations of "elegance, fragrance, fashion and taste", core ideas or benefits of the brand. The phonetic adaptation of the Chinese name of "Estee Lauder" help the brand build a consistent global image in Chinese market and promote perceived quality of Estee Lauder products by offering a feeling of western country of origin. Some one-syllable brand names are translated into two-syllables or three-syllables and two-syllables into three-syllables or four-syllables because word with two and three syllables are often adopted in Chinese naming to meet cultural-psychological needs of Chinese consumers. Three-syllables are translated into four-syllables usually because the brand intends to distinguish itself from other brands and other brand strategies. For example, Olay, a two-syllable skin care brand, is translated as "Yu lan you" (玉兰油) in Chinese, a three-syllable name; Fresh, a one-syllable natural high-end skincare brand, is translated as "Fu lei shi" (馥蕾 诗), a three-syllable name". Origins, a beauty brand powered by nature and proven by science, has three syllables, literally means "the point from which sth starts" and associates its products with the sources of the product's potent ingredients in their natural habitats and local and cultural histories. It is translated as "Yue mu zhi yuan" (悦木之源) in Chinese. The translated Chinese name has different pronunciation and syllables from those of the original name. This translated name selects four-syllable word because the brand intends to distinguish itself obviously from other competition brands such as Innisfree (Yue shi feng yin 悦诗风吟), Annunciation (Shi yue tian shi 十月天使).

The above analysis shows that phonetic adaptation can be adopted in brand translation. The translator may adapt the pronunciation of the Chinese name to that of the English counterpart, or adapt the syllables of the Chinese name to that of the English name, or adapt the syllables to Chinese culture.

\subsection{Lexical Adaptation Strategies}

In brand translation, different vocabulary has different influences on associated meanings of a brand name and how to express the associated meanings. According to the above statistical analysis, traditionally, western cosmetic brand naming first intended to select proper names $(39.7 \%)$ such as the name of founder (s), a place, and a plant, then fabricated vocabulary $(23.8 \%)$ and phrases $(20.6 \%)$, last common vocabulary (15.9\%). Early western brands are usually named after founders, plants, rivers and places because these proper names ar e a sign of quality and can trigger positive associations relating to brand products. For instance, Pond's (Pang shi 旁氏), a brand or beauty and health care products introduced in 1846, and Chanel (Xiang naier 香奈儿), an early perfume brand founded in 1909, are both named after their founders. Vichy (Wei zi 薇姿), well-known drug and cosmetic brand established in 1931, is named after the town of Vichy, which is famous for its hot springs, and gets positive associations from the name of the town. Some western cosmetic brands prefer fabricated vocabulary such as Lea Nature (Li ya zi ran 丽雅自然), which is fabricated by "lea" and "nature". "Lea" means "an open area of land covered in grass" and "nature" refers to "all the plants, animals and things that exist in the universe that are not made by people" or "the way that things happen in the physical world when it is not controlled by people". The combination of "lea" and "nature" imply the property of "natural" and "organic".

When translated into Chinese, most brands prefer fabricated vocabulary $(67.4 \%)$ and common vocabulary $(20.6 \%)$. The data results show that the word sources in Chinese names are much different from those in their English counterparts. That is because the core benefits and associations have been changed a lot to adapt the needs of specific consumers in different periods and in different markets such as Guerlain, a French perfume, cosmetics and skincare brand founded in 1828, which has obtained rich associated meanings by the name exploited, developed and reinforced in the advertising strategy. When Guerlain intended to enter Chinese market, it adapted to the needs of Chinese consumers and got the Chinese name "Jiao lan 娇兰".

The above analysis shows that lexical adaptation can be adopted in brand translation when translating western 
cosmetic brands from English into Chinese. The translators may give up the original word sources and employ coined words which can trigger core associations desired by the brand and its potential consumers.

\subsection{Semantic Adaptation Strategies}

Semantically, the literal meanings, core associations and connotations of a brand name will impact how the potential consumers understand and deal with the brand information. The above statistical analysis shows that western cosmetic brands intend to select names with literal meanings $(100 \%)$ and neutral connotations $(79.4 \%)$, reflecting the core associations of the brands $(62.7 \%)$. While entering into Chinese market, these brands intend to have positive $(60.3 \%)$ names without literal meanings $(71.4 \%)$ but reflecting core associations of the brands $(60.3 \%)$. According to table 5, most of Chinese names $(85.7 \%)$ have different literal meanings from those English counterparts. English and Chinese are different linguistic systems so that it is not easy to get equivalence. And consumers in different markets probably will have different functional, emotional and symbolic needs, which make the Chinese word (s) with the same literal meaning not able to reflect the core associations desired by the brand. For instance, Belli, a brand that provides beautiful skin and peace of mind to women at any age or stage, including pregnancy and nursing. Belli is chosen as a brand name because it is a shorter version of the Italian word, bellissimo meaning very beautiful. It was translated as "Bi li 壁丽” to adapt to the pronunciation of the English name as well as the expectation of the product function of the potential consumers. "bi 壁" refers to "the belly", "li 丽" means "beautiful", and "Bi li 壁丽" as a whole means " to deliver trusted skin care solutions and make you have beautiful skin and enjoy peace of mind during any stage of your life: pregnancy, motherhood and beyond."

When it comes to the core associations relating to the brand, the data above show that most names in Chinese and English (59.6\% or 61.2\%), following the rules of brand naming, reflect the core associations desired by the brand. However, the core associations reflected by the names in Chinese and English may be consistent whereas the literal meanings of the names in Chinese and English are quite different. M.A.C, one of the world's cosmetics leading brands standing for Makeup Art Cosmetics, sells cosmetics of high quality that is intended for professional as well as everyday users, who are seeking for colorful, fashionable and creative makeup products. Its Chinese name "Mei ke 魅可”, adapting to two phonemes respectively, means "charming, attractive, colorful, fashionable", the core associations desired by the brand. The core associations reflected by the translated and original names can also be different because of the different aim-needs of the brand and its potential consumers. Vichy, a drug and cosmetic brand named after the town famous for its hot springs, has associated with the core functional benefits "natural, high-quality, keep one's skin healthy and hydrated". And its Chinese name "Wei zi 微姿” reflected “natural, healthy, security, charm and profession", the core emotional benefits desired by the consumers.

When it comes to connotations, many English names with neutral connotations (42.9\%) are translated into Chinese ones with positive connotations, which adapted to the positive connotation preferences of Chinese consumers. Lab Series, one of the original, men's only skincare brands, refers to "a series of products for men's skin" and implies high-tech, high-performance men's skincare that gets real results. Its Chinese name "Lang shi 朗仕” focuses on its potential consumers "successful men" implying men's only skincare brands and has positive connotation with the characters “lang 朗” and “shi 仕” . Aramis, the first prestige men's fragrance, is named after a Turkish root known for its aphrodisiac properties to show its cool sophistication and timeless appeal. The Chinese name "Ya nan shi 雅男士" implies prestige men as the potential consumers of the brand and also has a positive connotation with the character "ya 雅".

When it comes to cultural connotations, the above statistical analysis shows that most of Chinese brand names are infused with English (45.2\%) or Chinese cultural connotations (37.3\%). English cultural connotations infused in Chinese names are to meet the consumers' desire for worshipping everything foreign and promote brand image. Sofina, a Japanese skincare brand, literally means "wise". The literal meaning of its Chinese name “Su fei na 苏菲娜” is different from that of its English name. It refers to a name of a western girl implying who will be the brand's potential consumers and the origin of region. In this way, is English cultural connotation augmented. Chinese cultural connotation augmented in the translated Chinese names are to adapt to cultural psychology of Chinese consumers. Clarins, a French luxury skin care, cosmetics and perfume brand, is named after its founder. However, its Chinese name "Jiao yun shi 娇韵诗” is meaningless literally as a whole whereas every character is meaningful and can trigger rich associations and positive connotations preferred by Chinese consumers.

The above analysis shows that semantic adaptation can be adopted in brand translation when translating western cosmetic brands from English into Chinese. The translators may take the aim-needs of the brand company and 
Chinese consumers into consideration, reposition the brand and follow the semantic adaptation strategies summarized above.

\section{Conclusion}

This paper selects 126 western cosmetic brands in Chinese market randomly, analyzes and compares the linguistic features of the brand names in English and Chinese. The results of the analysis indicate that, to select a desired Chinese name, phonetic adaptation, lexical adaptation and semantic adaptation could be adopted to meet the aim-needs of the brand company and the potential consumers.

This paper provides proper strategies for western cosmetic brand translation, which has great realistic significance on improving the quality of brand translation, promoting the localization of international brands, and the internationalization of Chinese brands. Meanwhile, with the aim-adaptation approach, this paper analyzes and compares brand names in the context of aim-needs of both the brand company and the potential consumers, providing reasonable grounds for brand name selection with a hope to expand research dimensions in the pragmatic translation theories.

In addition, this paper only discusses linguistic adaptation strategies in western cosmetic brand translation from English into Chinese. The effectiveness of the strategies is yet to be tested and verified in other industry brand translation and in other languages.

\section{References}

De Mooij, M. K. (2010). Global Marketing and Advertising: Understanding Cultural Paradoxes (3rd ed.). SAGE Publications, Thousand Oaks, CA.

Dong, L. C., \& Helms, M. M. (2001). Brand Name Translation Model- A Case Analysis of US Brands in China. Journal of Brand Management, 9(2), 99-115.

Fang, M. Z. (2011). Applied Translation in China. Chinese Translations Journal, 3.

Francis, J., Lam, J., \&Walls, J. (2002). The Impact of Linguistic Differences on International Brand Name Standardization: A Comparison of English and Chinese Brand Names of Fortune-500 Companies. Journal of International Marketing, 10(1), 98-116.

Gardner, B. B., \& Sidney, J. L. (1955). The Product and the Brand. Harvard Business Review, 33(2), 33-39.

Hong, F. C., Pecotich, A., \& Schultz, C. J. (2002). Brand Name Translation: Language constraints, product attributes, and Consumer Perceptions in East and Southeast Asia. Journal of International Marketing, 10(2), $29-45$.

Kohli, C., \& Douglas, W. L. (1997). Creating Effective Brand Names: A Study of the Naming Process. Journal of Advertising Research, 37(1), 67-75.

Li, F., \& Shooshtari, N. H. (2003). Brand Naming in China: Sociolinguistic Implications. The Multinational Business Review, 11(3), 3-18.

Liu, J. F. (2015). Strategic Principles for Translating Brand Names Featuring Multiple Meaning-Senses. Foreign Language and Literature, (5), 122-127.

Liu, J. F., \& He, Z. R. (2015). A Pragmatic Approach to Brand Renaming: More Considerations for Subjectivity in Translation. Chinese Translators Journal, (2), 103-106.

Nord, C. (1997). Translation as a Purposeful Activity: Functionalist Approaches Explained. Manchester: St. Jerome Publishing.

Schmitt, B., \& Zhang, S. (2012). Selecting the Right Brand Name: An examination of Tacit and Explicit Linguistic Knowledge in Name Translations. Journal of Brand Management, 19(8), 655-665, https://doi.org/10.1057/bm.2011.62

Shiao-Yun, C. (2009). Informative Meaning of Signs: Brand Naming and Globalization in China. Social Semiotics, 19(3), 329-344. https://doi.org/10.1080/10350330903072680

Vermeer, H. J. (1989). Skopos und Translationsauftrag-Aufsatze. Heidelberg: Universitat (thw- translatorisches handeln wissenschaft 2), 1989, second edition 1990.

Verschueren, J. (1999). Understanding Pragmatics. London: Edward Arnold Ltd.

Villar, M., Ai, D., \& Segev, S. (2012). Chinese and American perceptions of foreign-name brands. Journal of Product \& Brand Management, 21(5), 341-349. https://doi.org/10.1108/10610421211253632 
Wind, Y. J. (1982). Product policy, Methods and Strategy. Reading, MA: Addison Wesley.

Zeng, L. S. (2014). A Systematically Integrated Study of Translatology. Foreigh Language Teaching and Research Press.

Zhang, S., \& Schmitt, B. H. (2001). Creating local brands in multilingual international markets. Journal of Marketing Research, 38(2), 313-325.

\section{Copyrights}

Copyright for this article is retained by the author(s), with first publication rights granted to the journal.

This is an open-access article distributed under the terms and conditions of the Creative Commons Attribution license (http://creativecommons.org/licenses/by/4.0/). 